\title{
Diagnostic Value of Adenosine Deaminase and Its Isoforms in Type II Diabetes Mellitus
}

\author{
Bagher Larijani, ${ }^{1}$ Ramin Heshmat, ${ }^{2}$ Mina Ebrahimi-Rad, ${ }^{3}$ \\ Shohreh Khatami, ${ }^{3}$ Shirin Valadbeigi, ${ }^{3}$ and Reza Saghiri ${ }^{3}$ \\ ${ }^{1}$ Endocrinology and Metabolism Research Center, Endocrinology and Metabolism Clinical Sciences Institute, \\ Tehran University of Medical Sciences, Tehran, Iran \\ ${ }^{2}$ Chronic Diseases Research Center, Endocrinology and Metabolism Population Sciences Institute, \\ Tehran University of Medical Sciences, Tehran, Iran \\ ${ }^{3}$ Department of Biochemistry, Pasteur Institute of Iran, Tehran, Iran
}

Correspondence should be addressed to Reza Saghiri; saghiri@pasteur.ac.ir

Received 14 June 2016; Revised 14 August 2016; Accepted 1 November 2016

Academic Editor: Ali-Akbar Saboury

Copyright (C) 2016 Bagher Larijani et al. This is an open access article distributed under the Creative Commons Attribution License, which permits unrestricted use, distribution, and reproduction in any medium, provided the original work is properly cited.

Background and Aims. In the present study, we have investigated the activity of adenosine deaminase (ADA) as a diagnostic marker in type 2 (or II) diabetes mellitus (T2DM). Design and Methods. The deaminase activity of ADA1 and ADA2 was determined in serum from 33 patients with type 2 (or II) diabetes mellitus and 35 healthy controls. We also determined the proportion of glycated hemoglobin (HbAlc). Results. Our results showed significant differences between total serum ADA (tADA) and ADA2 activities in the diabetic groups with HbAlc $<8(\%)$ and HbAlc $\geq 8(\%)$ with respect to the values in healthy individuals $(p<0.001)$. ADA2 activity in patients with high HbAlc was found to be much higher than that in patients with low $\operatorname{HbAlc}(p=0.0001)$. In addition, total ADA activity showed a significant correlation with HbAlc $(r=0.6, p<0.0001)$. Conclusions. Total serum ADA activity, specially that due to ADA2, could be useful test for the diagnosis of type 2 (or II) diabetes mellitus.

\section{Introduction}

Diabetes mellitus is a common disorder of glucose homeostasis which grows epidemically. The number of people diagnosed with T2DM is estimated about 380 million by the World Health Organization. This number is expected to increase to 592 million people by the year 2035 [1]. Glycosylated hemoglobin (HbAlc) has been suggested by International Diabetes Federation (IDF) for diagnosis of diabetes. HbAlc is supposed to be the best test for longterm control of blood glucose [2]. Metabolic disturbance and immunological imbalance are two important key factors in type 2 diabetes mellitus. Insulin deficiency and insulin resistance are the most important metabolic factors in type 2 diabetes. Immunological disturbance in type 2 diabetic individuals has been associated with cell-mediated immunity and inappropriate T-lymphocyte function [3]. Adenosine deaminase (adenosine aminohydrolase, EC 3.5.4.4, $\mathrm{ADA}$ ) is one of the key enzymes of purine nucleoside metabolism that catalyzes the deamination of adenosine and deoxyadenosine to inosine and deoxyinosine, respectively. ADA, an enzyme essential for the differentiation and proliferation of lymphocytes and monocyte, macrophage system, has been used for monitoring several immune system diseases. This enzyme was considered as a suitable marker of cell-mediate immunity. $T$ cells are the recipient of adenosine signaling produced by $\mathrm{B}$ cells. Adenosine decreases the activation of $\mathrm{T}$ cells. ADA that exists on the surface of B lymphocytes could inactivate the adenosine signal. ADA is localized on the external surface of erythrocytes this might be in turn associated with inactivation of extracellular adenosine. Binding complexing protein on surface of fibroblasts has been considered to be a surface receptor for ADA $[4,5]$. Adenosine deaminase includes two isoforms with unique biochemical properties. ADAl can exist as a monomer with $30-40 \mathrm{KDa}$ molecular weight or as a dimer with $280 \mathrm{KDa}$ molecular 
weight while ADA2 is a $110 \mathrm{KDa}$ protein $[6,7]$. The ADA1 is found in all cells with the highest activity in lymphocytes and monocytes, whereas ADA2 is the predominant isoform in the serum of normal subjects. The major source of ADA2 is likely to be monocyte-macrophage system that produced it in response to pathogen factors and encoded by CECRI gene. ADA2 is a member of the new family of growth factors called ADCFs (ADA-related growth factors). ADA2 is strongly increased in inflammatory diseases such as rheumatoid arthritis and tuberculosis, AIDS, and diabetes [8-10]. Studies have shown that the protein attached to ADA1 molecule is identified to be CD26/DPPIV [11]. CD26 is a T cell activating antigen and transmembrane glycoprotein. On the surface of T-lymphocytes, ADA binds to CD26 via A2bR (adenosine A2B receptors) [12]. Moreover, CD26/DPPIV inactivates the incretin hormone glucagon-like peptide-1 (GLP-1) and glucose dependent insulin tropic polypeptide (GIP). DPPIV inhibitors stabilize endogenous GLP-1 at physiological concentration, induce insulin secretion in glucosedependent manner and prevent the degradation of GLP-1 [13]. Recent studies show ADA increase in tissue of diabetic rats. ADA increased activity was reported in the lymph nodes and splenocyte of diabetes-prone BB rats [14]. Genetically, ADA locus in chromosome 20 is associated with locus type 2 diabetes [15]. Adenosine deaminase is an important enzyme for modulating adenosine concentration. Adenosine stimulates insulin activity via several processes such as glucose transport, lipid synthesis, pyruvate dehydrogenase activity, and Leucine oxidation. Adenosine plays an important role in bioactivity of insulin and regulates insulin activity in various tissues such as liver, myocardium white adipose, and skeletal muscles [16,17]. Adenosine potentiates the action of insulin in myocardium and adipose tissue and inhibits liver and skeletal muscle. Adenosine mimics the action of insulin on glucose and lipid metabolism in adipose tissue [18]. Adenosine has antilipolysis property in adipose tissue and increases insulin sensitivity for glucose transport [19]. Adenosine increases accessibility about $25 \%$ of GLUT4 to cell surface for glucose transportation [20]. Adenosine with binding to A1 receptor increases the accumulation of the insulin-induced PIP3 and $\mathrm{PKB}$ in postreceptor phase [21]. Adenosine has also been shown to increase gluconeogenesis and glycogenolysis via increasing cyclic AMP (CAMP) by stimulation of hepatic adenylate cyclase through adenosine $\mathrm{A} 2 \mathrm{a}$ receptor binding in liver. Both or either of these actions causes the increase of local insulin resistance and glucose output from the liver [22]. In this study we have investigated the alternation of serum ADA activities and its mechanism in type 2 diabetic patients.

\section{Material and Method}

2.1. Patients. 33 patients with type 2 diabetes who referred to Diabetes Center of Shariati Hospital were diagnosed by the endocrinologist and their blood was drawn during 6 months. No patients displayed any kind of infection or inflammatory diseases which lead to increase in ADA. This group was divided into two groups according to hemoglobin Alc (HbAlc) level, namely, patients whose HbAlc levels were less than 8 and those with HbAlc level more than 8 . Blood was also drawn from 35 healthy individuals as the control subjects.

\subsection{Blood Sampling Protocol}

2.2.1. Serum Samples. Blood samples were obtained from patients and healthy subjects after $12 \mathrm{~h}$ fasting. Fasting blood samples were collected to centrifugation at 3,000 rpm for $10 \mathrm{~min}$ at $4^{\circ} \mathrm{C}$ to obtain serum. All samples were stored at $-80^{\circ} \mathrm{C}$ after separation.

2.2.2. Measurement of Adenosine Deaminase. The ADA activity was assayed by the ADA kit of Diazyme Laboratories and with model 912 type Autoanalyzer (Hitachi Co. Ltd., Tokyo, Japan). The ADA assay is based on enzymatic deamination of adenosine to inosine in this kit. Inosine is converted to hypoxanthine by purine nucleoside phosphorylase. Hypoxanthine is then converted to uric acid and hydrogen peroxide $\left(\mathrm{H}_{2} \mathrm{O}_{2}\right)$ by xanthine oxidase. $\mathrm{H}_{2} \mathrm{O}_{2}$ is further reacted with $\mathrm{N}$ ethyl-N-(2-hydroxy-3-sulfopropyl)-3-methylaniline and 4aminoantipyrine in the presence of peroxidase to generate quinone dye which is monitored in a kinetic manner.

To distinguish between the ADA1 and ADA2 forms, the ADA activity was measured using the same technique with and without EHNA (erythro-9-(2-hydroxy-3-nonyl) adenine), obtained from Sigma-Aldrich (St. Louis, MO, USA). EHNA, a potent selective inhibitor of ADA1, was used at final concentration of $0.1 \mathrm{mmol} / \mathrm{L}$. In its presence, only the ADA2 isoform is active. The ADA1 activity is then calculated by subtracting the ADA2 activity from the total ADA activity.

\subsection{Assessment of Glycated Hemoglobin (HbAlc). Diazyme} direct enzymatic $\mathrm{HbAlc}$ analysis was evaluated on the Hitachi 912 Autoanalyzer (Hitachi Co. Ltd., Tokyo, Japan) using blood samples. We have applied simple enzymatic assay for $\mathrm{HbA1C}$ using neutral protease and FPOX. Preparation of samples was carried out by mixing $500 \mu \mathrm{L}$ of lysis buffer with $25 \mu \mathrm{L}$ of whole blood and incubating for $10 \mathrm{~min}$ at room temperature.

2.4. Statistical Analysis. All results were expressed in terms of mean \pm standards deviation (SD). Data were analyzed by Package for Social Sciences (SPSS) version 16. Statistical differences between patient groups and controls were performed by one-way ANOVA test. Correlation between the ADA and HbAlc was measured by means of Pearson's Correlation Coefficient $(r)$. HbAlc was expressed as a percentage. BMI was calculated as weight $(\mathrm{kg}) /$ height $^{2}\left(\mathrm{~m}^{2}\right)$. $p$ value $<0.01$ was considered statically significant.

\section{Results}

This study was carried out on 16 patients with $\mathrm{HbAlc} \geq 8$ who were designated poorly controlled DM and 17 patients with $\mathrm{HbAlc}<8$ who were well controlled and 35 healthy individuals as control subjects. Mean $\pm \mathrm{SD}$ values of tADA, ADA1, and ADA2 were found in healthy subjects. Results are shown in Table 1. 
TABLE 1: ADA and its isoforms activities in T2DM patients based on low and high HbAlc comparison with healthy controls.

\begin{tabular}{|c|c|c|c|c|}
\hline \multirow[t]{2}{*}{ Groups } & & \multirow{2}{*}{$\begin{array}{l}\text { tADA } \\
\text { (IU/L) }\end{array}$} & \multirow{2}{*}{$\begin{array}{l}\text { ADA2 } \\
\text { (IU/L) }\end{array}$} & \multirow{2}{*}{$\begin{array}{l}\text { ADA1 } \\
(\mathrm{IU} / \mathrm{L})\end{array}$} \\
\hline & & & & \\
\hline \multirow{6}{*}{$\begin{array}{l}\text { Low } \\
\text { HbAlc }\end{array}$} & Mean & 16.18 & 9.41 & 6.76 \\
\hline & $N$ & 17 & 17 & 17 \\
\hline & Std. deviation & 2.67 & 3.74 & 1.67 \\
\hline & Minimum & 13 & 6 & 2.00 \\
\hline & Maximum & 24 & 22 & 8.00 \\
\hline & Variance & 7.15 & 14.00 & 2.81 \\
\hline \multirow{6}{*}{$\begin{array}{l}\text { High } \\
\text { HbAlc }\end{array}$} & Mean & 22.44 & 13.94 & 8.50 \\
\hline & $N$ & 16 & 16 & 16 \\
\hline & Std. deviation & 7.420 & 5.19 & 3.96 \\
\hline & Minimum & 16 & 8 & 4.00 \\
\hline & Maximum & 45 & 24 & 22.00 \\
\hline & Variance & 55.06 & 26.99 & 15.73 \\
\hline \multirow{6}{*}{ Control } & Mean & 14.00 & 7.66 & 6.34 \\
\hline & $N$ & 35 & 35 & 35 \\
\hline & Std. deviation & 1.680 & 1.73 & .48 \\
\hline & Minimum & 11 & 5 & 6.00 \\
\hline & Maximum & 17 & 11 & 7.00 \\
\hline & Variance & 2.82 & 2.99 & .23 \\
\hline
\end{tabular}

TABLE 2: Anthropometric measurements and clinical parameters of T2DM patients and healthy control.

\begin{tabular}{lccc}
\hline Characteristics & T2DM $(n=33)$ & Controls $(n=35)$ & $p$ value \\
\hline Age $($ years $)$ & $60.2 \pm 8.7$ & $65.8 \pm 9.2$ & 0.0008 \\
BMI $\left(\mathrm{kg} / \mathrm{m}^{2}\right)$ & $29.5 \pm 7.00$ & $21.3 \pm 6.78$ & 0.005 \\
FPG $(\mathrm{mg} / \mathrm{dL})$ & $156.7 \pm 10.3$ & $92.6 \pm 7.58$ & $<0.0001$ \\
\hline
\end{tabular}

Data are shown as the means \pm SD. BMI, body mass index; T2D, type 2 diabetes mellitus; FPG, fasting plasma glucose; $p<0.001$, ANOVA test analysis.

The increasing of tADA, ADA1, and ADA2 activity in subjects with $\mathrm{HbAlc}<8$ and those with $\mathrm{HbAlc} \geq 8$ is significant in comparison with healthy ones $(p<0.001)$.

Anthropometric measurements and clinical parameters of the study subjects are shown in Table 2 . As illustrated in the table, serum ADA activity in T2DM patients with HbAlc high and low was significantly higher than healthy group. These variations specially increased ADA2 in $\mathrm{HbAlc} \geq 8$ in comparison with $\mathrm{HbAlc}<8$ is investigated to be more.

As shown in Figure 1, we also observed significant positive correlation between serum ADA activities and HbAlc ( $r=$ $0.6, p<0.0001)$.

\section{Discussion}

Type 2 diabetes is accompanied with collection of clinical and biochemical disorders which have been called metabolic syndrome X. These disorders include center obesity, hypertension, atherosclerosis, hypertriglyceridemia, increased cholesterol and LDL, and decreased HDL. The action of cytokines

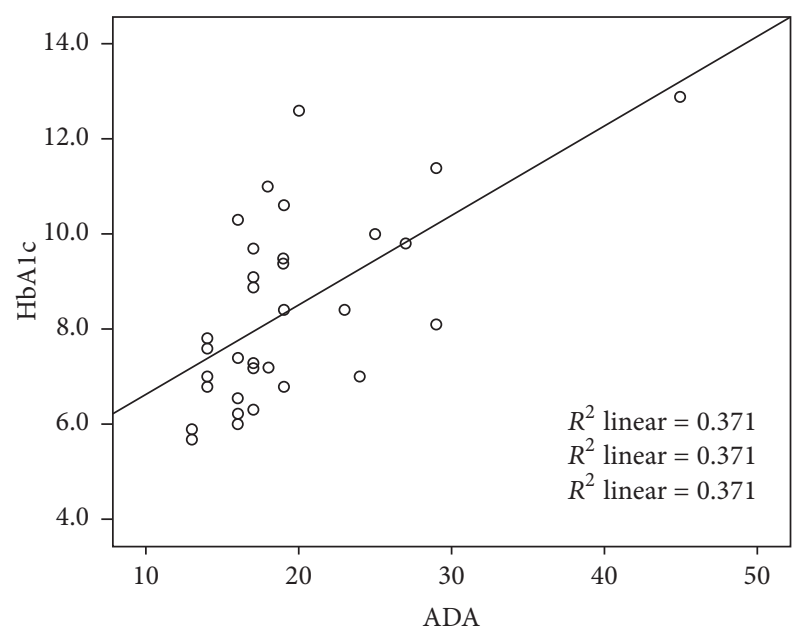

FIgURE 1: The correlation between HbAlc and tADA in diabetic patients.

on the brain, liver, endothelium, and adipose tissue is a major factor of metabolic syndrome X. Cytokines stimulate the acute-phase proteins. In the short term, the acute-phase protein has survival values and regulates homeostasis and in long-term produces diseases [23]. These cytokines such as IL-1, IL-6, and TNF- $\alpha$ are produced from monocytes, macrophage, and adipose tissue. Insulin resistance and hyperglycemia increase the effect of cytokines on the liver and cause the secretion of IL- 6 and TNF- $\alpha$ from monocytes and macrophage [24]. On the other hand, production of cytokines from monocytes and macrophage and the increase in acutephase proteins elevate insulin resistance [25]. Aging, certain 
dietary components, smoking, and obesity are important factors in cytokine increase and immunity disturbance in type 2 diabetes. Immunity disturbance does not happen in all T2DM individuals and other major factors such as genetics, cytokine sensitivity, and acute-phase response contribute to its existence. Cytokine imbalance effects ADA activity [26]. Variation in cytokines especially cytokines which were produced by Thl cells is associated with the increase in ADA serum activity. It also activates monocyte-macrophage cell system [27]. Defect in insulin activity required for Tlymphocytes in diabetes leads to abnormal T-lymphocyte proliferation and enhanced ADA activity [28]. The effects of ADA on T-lymphocytes and cytokines represent it as a suitable marker of cell-mediated immunity. The increased ADA levels in inflammatory and autoimmune diseases such as rheumatoid arthritis, tuberculosis, and systemic lupus erythematosus (SLE) make its role more significant. Likewise, immune system and increase and concentration of extracellular adenosine are considered as other major factors in ADA increase. Adenosine is a local hormone which regulates many biological activities. Adenosine causes coronary vasodilatation, bradycardia, inhibition of platelet aggregation, renal vasoconstriction, and regulation of channel ion activity. These processes are carried out via adenosine receptors (A1, $\mathrm{A} 2 \mathrm{a}, \mathrm{A} 3$, and $\mathrm{A} 2 \mathrm{~b}$ ). In normal conditions, adenosine contains low concentration lesser than $1 \mu \mathrm{m}$ and is risen under metabolically conditions such as stress and tissue injuries to $4-10 \mu \mathrm{m}$ [29]. Extracellular adenosine concentration is regulated by two mechanisms of transportation of adenosine across the cell membrane and enzymatic regulation of adenosine concentration and can be activate adenosine receptors [9]. There exist two types of nucleoside transporters across the plasma membrane, the equilibrative facilitateddiffusion transport (ENT) and concentrative $\mathrm{Na}^{+}$dependent transporters (CNT). Inhibition of these transporters potentiates the action of adenosine. Enzymatic regulation of adenosine concentration in mammals is dependent upon activity of 5-nucleotidase and two utilizing enzymes: adenosine deaminase and adenosine kinase [30]. Investigations on diabetic individuals show the increase in the value of adenosine. Reduction in the activity of adenosine kinase is a major factor in the increase of adenosine in these patients [31]. In addition, variation in adenosine receptors and transporters can change tissue sensitivity to adenosine [32-34]. Studies on adenosine concentration and its effect on cell functions show the important role of adenosine in glucose metabolism. In the range of $0.003-0.5 \mu \mathrm{mol} / \mathrm{kg}$, adenosine lowers the serum fatty acids and serum insulin. On the other hand, in the range of $0.5-50 \mu \mathrm{mol} / \mathrm{kg}$, its effect on hepatic A2a receptors stimulates gluconeogenesis and the increase of serum glucose [35]. The increase of adenosine level with decrease in adenosine kinase in diabetes results in deamination of adenosine and the increase in adenosine deaminase. In fact, the increase in ADA activity is a protective mechanism against adenosine elevation [26]. When the adenosine concentration is strongly elevated, ADA enzyme catalyzes deamination of adenosine via ADA1 and ADA2 (ADA-related growth factors) isoforms and decreases its concentration. Since the ADA2 increases CD4-T cells, it can be useful in stimulating immune system [10]. T-lymphocytes abnormal proliferation, increased secretion cytokines, and increased extracellular adenosine are major factors in the elevation of ADA. The increase of ADA in diabetic patients leads to metabolic changes of insulin especially in adipose tissues. ADA in adipose tissue causes the increase in lipolysis, the augmentation of hyperlipidemia, and the disturbance in antilipolysis activity. High concentration of fatty free acids (FFA) derived from lipolysis elevation causes oxidative phosphorylation and ATP retention in adipocytes [36]. ADA impairs PKB and PI3P production in insulin postreceptor phase and reduces insulin sensitivity in adipocytes [20]. Moreover, endogenic reduction of adenosine by ADA decreases insulin ability for the activation of tyrosine kinase receptor in submaximal concentration of insulin. Therefore, diabetic adipocyte cells require more insulin concentration [21]. ADA reduces GLUT4 accessibility to cell surface for glucose transporters [19]. Adenosine deamination is guided toward hypoxanthine uric acid production and xanthine oxidase enzyme in this process causes superoxides production. The increase membrane peroxidation alters $\mathrm{Na}^{+}, \mathrm{K}^{+}$, ATPase activity, and transport of metabolites across the membrane. The increase and production of superoxides enhance the risk of cardiovascular diseases in diabetic patients. ADA causes the high rate of uric acid which shows significant correlation between the ADA levels and uric acids in diabetics $[21,37]$. On the other hand, high glucose level causes the increase in ADA attached DPPIV protein. Accordingly, the increase in glucose of diabetics leads to high DPPIV-ADA and increase in DPPIV-ADA results in incretin reduction and insulin secretion. Insulin deficiency and irregulation of glucose are major factors in the elevation of ADA in diabetes. Therefore, insulin can be a good quality way of $\mathrm{ADA}$ reduction. Insulin reduces ADA activity in diabetic tissues and regulates local concentration of adenosine. Some herbal drugs can reduce ADA and control blood glucose [38]. The ADA-CD26/DPPIV interaction is inhibited by the cell surface glycoprptein (gp120) in HIV1-infected individuals and it might result in increasing levels of serum ADA. ADACD26/DPPIV complex plays a main role in the regulation of immune activity and cell adhesion [39, 40]. ADA alongside other immunomodulatory enzymes acts as a deconstructive oxidative marker in diabetes and plays an important role in progression of its complications. ADA increase, especially ADA2, may serve as an immunoenzyme marker in the pathology of type 2 diabetes mellitus.

\section{Abbreviations}

HbAlc: Glycated hemoglobin

T2DM: Type II diabetes mellitus

ADA: Adenosine deaminase

DPPIV: Dipeptidyl peptidase 4

PIP3: Phosphatidylinositol-trisphosphate

PKB: Protein kinase B

AMP: Adenosine monophosphate

HDL: High-density lipoprotein

LDL: Low-density lipoprotein

IL: Interleukin 
TNF- $\alpha$ : Tumor necrosis factor alpha

FPOX: Fructosyl peptide oxidase

ADGFs: Adenosine-related growth factors.

\section{Competing Interests}

The authors declare no conflict of interests.

\section{Acknowledgments}

This work was supported by Endocrinology and Metabolism Research Institute. This study represented that ADA could be a useful alternative test to diagnosis of diabetes mellitus.

\section{References}

[1] K. M. Goodrich, S. K. Crowley, D.-C. Lee, X. S. Sui, S. P. Hooker, and S. N. Blair, "Associations of cardiorespiratory fitness and parental history of diabetes with risk of type 2 diabetes," Diabetes Research and Clinical Practice, vol. 95, no. 3, pp. 425431, 2012.

[2] L. Czupryniak, "Guidelines for the management of type 2 diabetes: is ADA and EASD consensus more clinically relevant than the IDF recommendations?" Diabetes Research and Clinical Practice, vol. 86, no. 1, pp. S22-S25, 2009.

[3] M. S. Prakash, S. Chennaiah, Y. S. R. Murthy, E. Anjaiah, S. Ananda Rao, and C. Suresh, "Altered adenosine deaminase activity in type 2 diabetes mellitus," Journal, Indian Academy of Clinical Medicine, vol. 7, no. 2, pp. 114-117, 2006.

[4] J. M. Aran, D. Colomer, E. Matutes, J. L. Vives-Corrons, and R. Franco, "Presence of adenosine deaminase on the surface of mononuclear blood cells: immunochemical localization using light and electron microscopy," Journal of Histochemistry and Cytochemistry, vol. 39, no. 8, pp. 1001-1008, 1991.

[5] R. Franco, J. M. Aran, D. Colomer, E. Matutes, and J. L. VivesCorrons, "Association of adenosine deaminase with erythrocyte and platelet plasma membrane: an immunological study using light and electron microscopy," Journal of Histochemistry and Cytochemistry, vol. 38, no. 5, pp. 653-658, 1990.

[6] J. P. J. Ngerer, S. H. Oosthulzeu, S. H. Bissbort, and W. J. Wermaak, "Serum adenosine deaminase: isoenzymes and diagnostic application," Clinical Chemistry, vol. 38, no. 7, pp. 1322-1326, 1992.

[7] M. Gupta and V. Nair, "Adenosine deaminase in nucleoside synthesis. A review," Collection of Czechoslovak Chemical Communications, vol. 71, no. 6, pp. 769-787, 2006.

[8] A. V. Zavialov, X. Yu, D. Spillmann, G. Lauvau, and A. V. Zavialo, "Structural basis for the growth factor activity of human adenosine deaminase ADA2," Journal of Biological Chemistry, vol. 285, no. 16, pp. 12367-12377, 2010.

[9] A. V. Zavialov and Å. Engström, "Human ADA2 belongs to a new family of growth factors with adenosine deaminase activity," Biochemical Journal, vol. 391, no. 1, pp. 51-57, 2005.

[10] R. Iijima, T. Kunieda, S. Yamaguchi et al., "The extracellular adenosine deaminase growth factor, ADGF/CECR1, plays a role in Xenopus embryogenesis via the adenosine/P1 receptor," The Journal of Biological Chemistry, vol. 283, no. 4, pp. 2255-2264, 2008.

[11] J. Kameoka, T. Tanaka, Y. Nojima, S. F. Schlossman, and C. Morimoto, "Direct association of adenosine deaminase with a
T cell activation antigen, CD26," Science, vol. 261, no. 5120, pp. 466-469, 1993.

[12] E. Gracia, K. Pérez-Capote, E. Moreno et al., "A2A adenosine receptor ligand binding and signalling is allosterically modulated by adenosine deaminase," Biochemical Journal, vol. 435, no. 3, pp. 701-709, 2011.

[13] D. J. Drucker, "Dipeptidyl peptidase-4 inhibition and the treatment of type 2 diabetes," Diabetes Care, vol. 30, no. 6, pp. 1335-1343, 2007.

[14] G. Wu and E. B. Marliss, "Deficiency of purine nucleoside phosphorylase activity in thymocytes from the immunodeficient diabetic BB rat," Clinical and Experimental Immunology, vol. 86, no. 2, pp. 260-265, 1991.

[15] M. M. Amoli, P. Amiri, M. Namakchian et al., "Adenosine deaminase gene polymorphism is associated with obesity in Iranian population," Obesity Research and Clinical Practice, vol. 1, no. 3, pp. 173-177, 2007.

[16] J. Espinal, R. A. John Challiss, and E. A. Newsholme, "Effect of adenosine deaminase and an adenosine analogue on insulin sensitivity in soleus muscle of the rat," FEBS Letters, vol. 158, no. 1, pp. 103-106, 1983.

[17] M. P. McLane, P. R. Black, W. R. Law, and R. M. Raymond, "Adenosine reversal of in vivo hepatic responsiveness to insulin," Diabetes, vol. 39, no. 1, pp. 62-69, 1990.

[18] T. Hoshino, K. Yamada, K. Masuoka et al., "Elevated adenosine deaminase activity in the serum of patients with diabetes mellitus," Diabetes Research and Clinical Practice, vol. 25, no. 2, pp. 97-102, 1994.

[19] S. M. Johansson, E. Lindgren, J.-N. Yang, A. W. Herling, and B. B. Fredholm, "Adenosine A1 receptors regulate lipolysis and lipogenesis in mouse adipose tissue-interactions with insulin," European Journal of Pharmacology, vol. 597, no. 1-3, pp. 92-101, 2008.

[20] S. J. Vannucci, H. Nishimura, S. Satoh, S. W. Cushman, G. D. Holman, and I. A. Simpson, "Cell surface accessibility of GLUT4 glucose transporters in insulin-stimulated rat adipose cells. Modulation by isoprenaline and adenosine," Biochemical Journal, vol. 288, no. 1, pp. 325-330, 1992.

[21] S. Takasuga, T. Katada, M. Ui, and O. Hazeki, "Enhancement by adenosine of insulin-induced activation of phosphoinositide 3-kinase and protein kinase B in rat adipocytes," The Journal of Biological Chemistry, vol. 274, no. 28, pp. 19545-19550, 1999.

[22] A. C. Warrier, N. Y. Rao, D. S. Kulpati, T. K. Mishra, and B. C. Kabi, "Evaluation of adenosine deaminase activity and lipid peroxidation levels in diabetes mellitus," Indian Journal of Clinical Biochemistry, vol. 10, no. 1, pp. 9-13, 1995.

[23] J. C. Pickup and M. A. Crook, "Is type II diabetes mellitus a disease of the innate immune system?" Diabetologia, vol. 41, no. 10, pp. 1241-1248, 1998.

[24] M. Morohoshi, K. Fujisawa, I. Uchimura, and F. Numano, "Glucose-dependent interleukin 6 and tumor necrosis factor production by human peripheral blood monocytes in vitro," Diabetes, vol. 45, no. 3, pp. 954-959, 1996.

[25] J. C. Pickup, "Inflammation and activated innate immunity in the pathogenesis of type 2 diabletes," Diabetes Care, vol. 27, no. 3, pp. 813-823, 2004.

[26] O. J. Cordero, F. J. Salgado, C. M. Fernández-Alonso et al., "Cytokines regulate membrane adenosine deaminase on human activated lymphocytes," Journal of Leukocyte Biology, vol. 70, no. 6, pp. 920-930, 2001. 
[27] M. Mokhtari, M. Hashemi, M. Yaghmaei et al., "Serum adenosine deaminase activity in gestational diabetes mellitus and normal pregnancy," Archives of Gynecology and Obstetrics, vol. 281, no. 4, pp. 623-626, 2010.

[28] F. Stentz and A. E. Kitabchi, "Activated T lymphocytes in type 2 diabetes: implications from in vitro studies," Current Drug Targets, vol. 4, no. 6, pp. 493-503, 2003.

[29] V. Kumar and A. Sharma, "Adenosine: an endogenous modulator of innate immune system with therapeutic potential," European Journal of Pharmacology, vol. 616, no. 1-3, pp. 7-15, 2009.

[30] T. Dolzal, "Adenosine deaminase. Review of physiological roles," 2001, http://www.entu.cas.cz/fyziol/seminars/ada/html.

[31] M. Sakowicz-Burkiewicz, K. Kocbuch, M. Grden, A. Szutowicz, and T. Pawelczyk, "Diabetes-induced decrease of adenosine kinase expression impairs the proliferation potential of diabetic rat T lymphocytes," Immunology, vol. 118, no. 3, pp. 402-412, 2006.

[32] T. Pawelczyk, M. Sakowicz, M. Szczepanska-Konkel, and S. Angielski, "Decreased expression of adenosine kinase in streptozotocin-induced diabetes mellitus rats," Archives of Biochemistry and Biophysics, vol. 375, no. 1, pp. 1-6, 1999.

[33] T. Pawelczyk, M. Grden, R. Rzepko, M. Sakowicz, and A. Szutowicz, "Region-specific alterations of adenosine receptors expression level in kidney of diabetic rat," The American Journal of Pathology, vol. 167, no. 2, pp. 315-325, 2005.

[34] M. Sakowicz, A. Szutowicz, and T. Pawelczyk, "Insulin and glucose induced changes in expression level of nucleoside transporters and adenosine transport in rat T lymphocytes," Biochemical Pharmacology, vol. 68, no. 7, pp. 1309-1320, 2004.

[35] B. Xu, D. A. Berkich, G. H. Crist, and K. F. LaNoue, "A1 adenosine receptor antagonism improves glucose tolerance in Zucker rats," The American Journal of Physiology, vol. 274, no. 2, part 1, pp. E271-E279, 1998.

[36] S. E. Mills, "Regulation of porcine adipocyte metabolism by insulin and adenosine," Journal of Animal Science, vol. 77, no. 12, pp. 3201-3207, 1999.

[37] N. Kurtul, S. Pence, E. Akarsu, H. Kocoglu, and Y. Aksoy, "Adenosine deaminase activity in the serum of type 2 diabetic," Acta Medica, vol. 47, pp. 33-35, 2004.

[38] T. Pawelczyk, M. Podgorska, and M. Sakowicz, "The effect of insulin on expression level of nucleoside transporters in diabetic rats," Molecular Pharmacology, vol. 63, no. 1, pp. 81-88, 2003.

[39] H. Fan, F. L. Tansi, W. A. Weihofen et al., "Molecular mechanism and structural basis of interactions of dipeptidyl peptidase IV with adenosine deaminase and human immunodeficiency virus type-1 transcription transactivator," European Journal of Cell Biology, vol. 91, no. 4, pp. 265-273, 2012.

[40] S. Ginés, M. Mariño, J. Mallol et al., "Regulation of epithelial and lymphocyte cell adhesion by adenosine deaminase-CD26 interaction," Biochemical Journal, vol. 361, no. 2, pp. 203-209, 2002. 

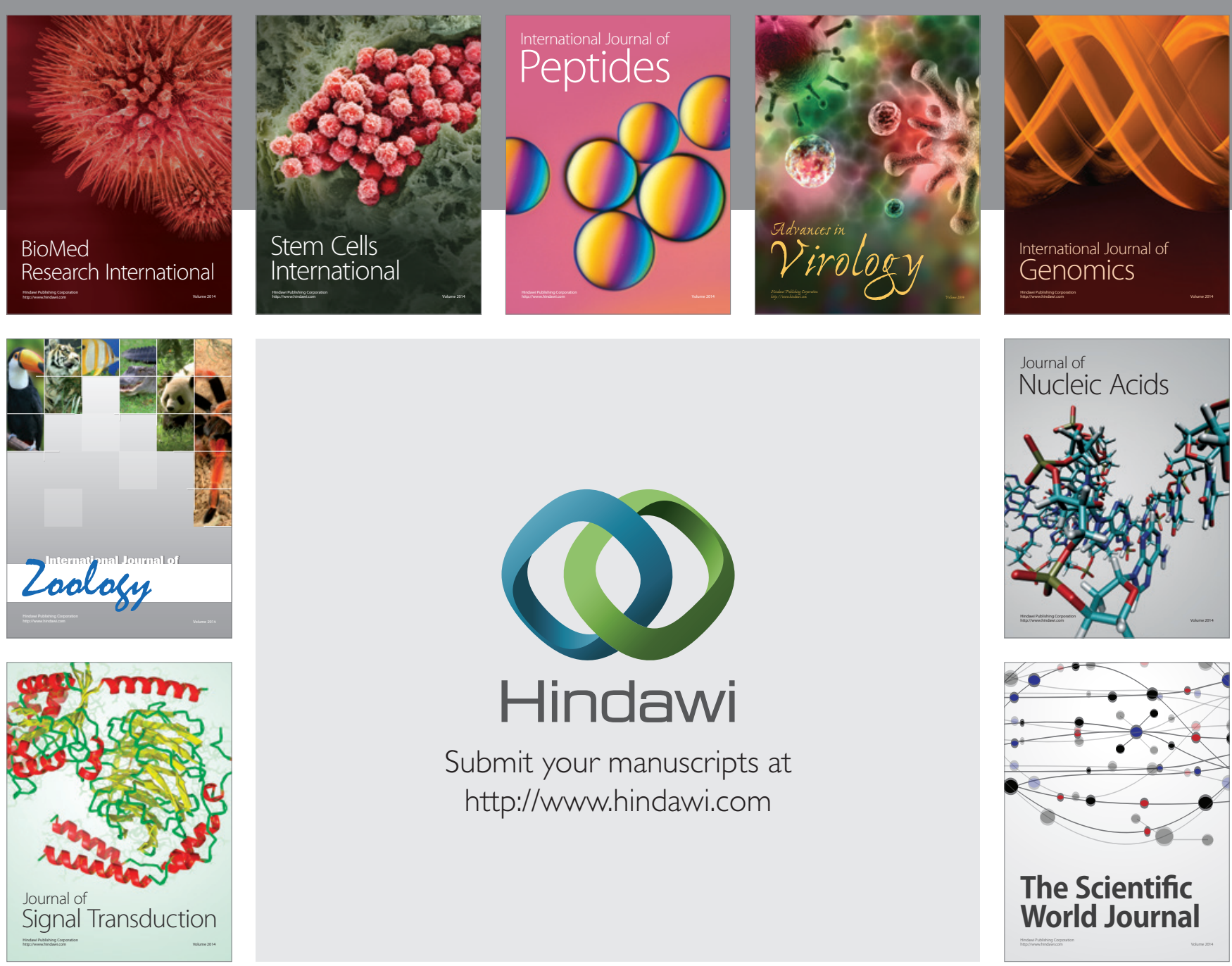

Submit your manuscripts at

http://www.hindawi.com
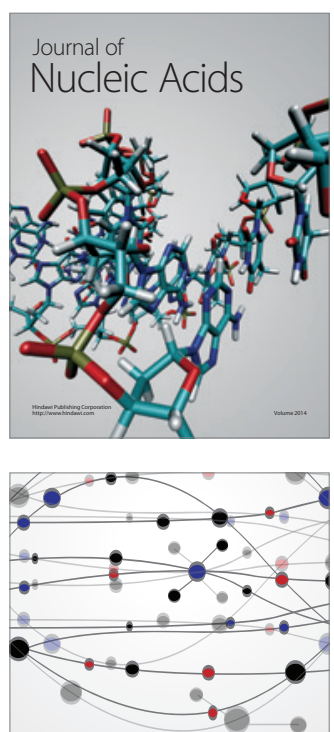

The Scientific World Journal
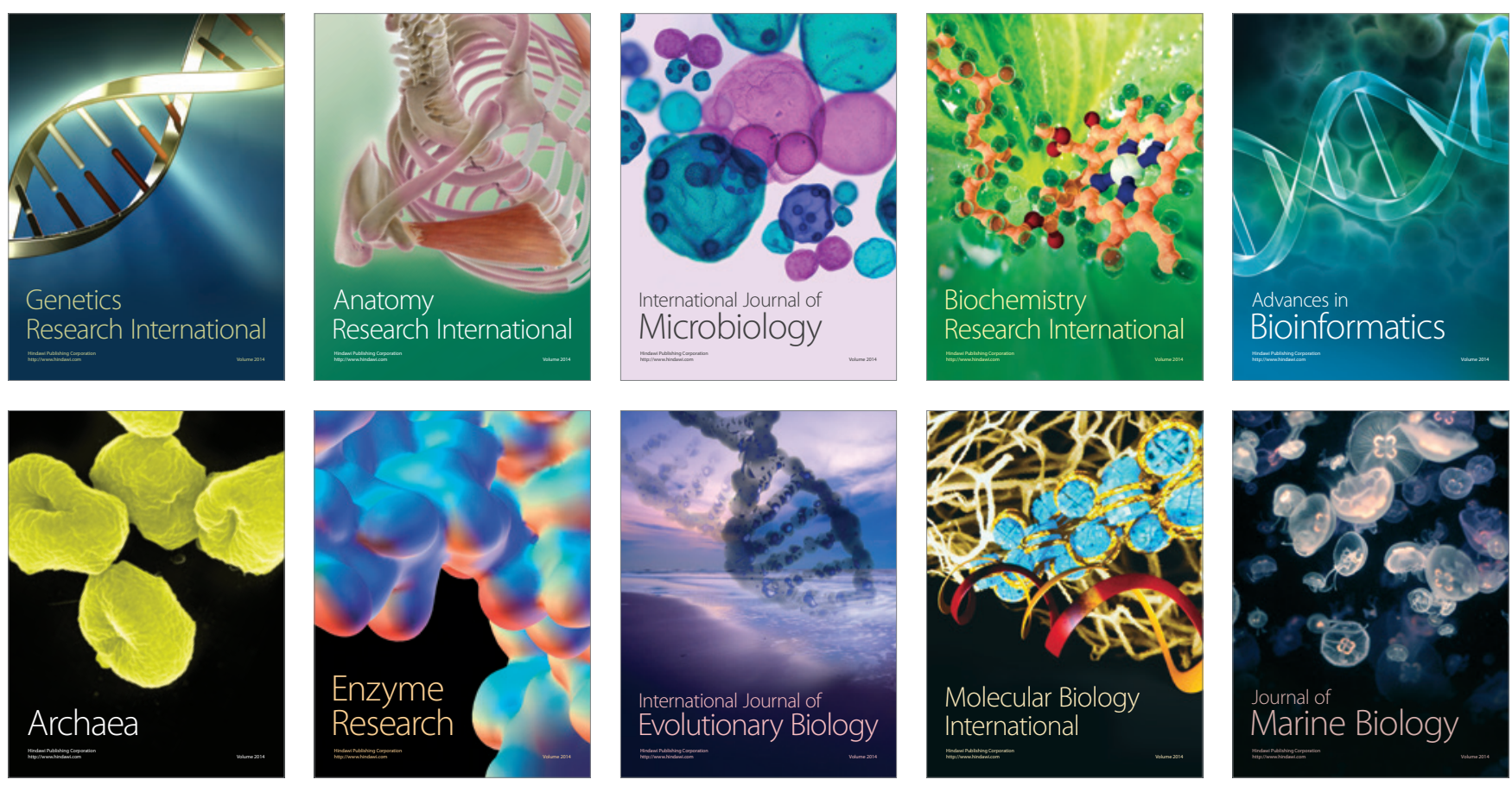